\title{
Faster and Further Morphosyntactic Development of CLIL vs. EFL Basque-Spanish Bilinguals Learning English in High-School
}

\author{
AMPARO LÁZARO IBARROLA* \\ Universidad Pública de Navarra
}

Received: 27 April 2011 / Accepted: 16 June 2011

\begin{abstract}
A general advantage in proficiency has been repeatedly reported for learners receiving Content and Language Integrated Learning (CLIL) when compared to learners who only receive English lessons. However, fine-grained studies addressing the aspects which make up this general advantage are still scarce. Within this context, this paper concentrates on the morphosyntactic development of two groups of (Basque-Spanish) adolescents learning English in high-school over a two-year period. One group $(n=15)$ received CLIL instruction and English classes while the other group $(n=11)$ only received English classes. The results indicate a clear advantage for the CLIL group, which seems to be at a further developmental stage. Nonetheless, both groups improve over the two years and, unlike previous claims in schools, no signs of fossilization are found although inaccuracies in inflection still exist. In light of these results, the value of increasing exposure in the form of CLIL lessons in high-school is discussed.
\end{abstract}

KEYWORDS: morphosyntactic development; CLIL; EFL; school context.

\section{RESUMEN}

Repetidamente se ha demostrado que los alumnos en programas de Adquisición Integrada de Contenidos y Lengua Extranjera (AICLE) son mejores que los alumnos que únicamente reciben clases de inglés. Sin embargo, pocos trabajos han especificado qué aspectos concretos de la lengua mejoran con estas metodologías. Este trabajo analiza, a lo largo de dos años, el desarrollo morfosintáctico de dos grupos de adolescentes bilingües (euskera-castellano) que aprenden inglés en el colegio. Un grupo $(n=11)$ solo recibe clases de inglés mientras que el otro $(n=15)$ también recibe clases de AICLE. Los resultados muestran que los alumnos AICLE presentan un mayor desarrollo morfosintáctico. También se muestra que ambos grupos evolucionan a lo largo de los dos años y, frente a trabajos anteriores, no hay signos de fosilización aunque los problemas flexivos persisten. Con estos resultados, se discute la validez de aumentar la exposición al inglés mediante programas AICLE en educación secundaria.

PALABRAS CLAVE: desarrollo morfosintáctico; AICLE; EFL; contexto escolar.

*Address for correspondence: Amparo Lázaro Ibarrola. Departamento de Filología y Didáctica de la Lengua. Universidad Pública de Navarra. Campus de Arrosadía. 31006 Pamplona. E-mail: amparo.lazaro@unavarra.es 


\section{INTRODUCTION}

\subsection{Justification}

According to Coyle (2007) the term Content and Language Integrated Learning (henceforth CLIL) was adopted by the European Network of Administrators, Researchers and Practitioners (EUROCLIC) in the mid 1990s and it can be defined as a methodology which encompasses any activity in which "[...] the foreign language is used as a tool in the learning of a non-language subject" (Coyle, 2007, p. 545).

CLIL methodologies have been claimed to raise learners' overall proficiency in the target language (Coyle, 2007) and a plethora of recent research carried out in this context has repeatedly confirmed this finding. However, it has been also pointed out that fine-grained studies that precisely address the aspects which make up these general gains in proficiency are very necessary to obtain a more complete picture of the effects of CLIL instruction (Dalton-Puffer, 2008; Dalton-Puffer, Nikula \& Smit, 2010; Van der Craen, Mondt, Allain and Gao, 2007). To address this need, some studies have set off to explore the effects of CLIL on the acquisition of morphosyntax and have obtained conflicting results: Some authors have found that morphosyntax greatly benefits from CLIL instruction (Dalton-Puffer, 2008; Ruiz Zarobe, 2008) whereas others, who have looked at the provision of specific morphemes, have found no differences between CLIL and non-CLIL learners (Bongartz, 2003; García Mayo and Villarreal Olaizola, 2011).

Within this context, the present study focuses on the morphosyntactic development of two groups of (Basque-Spanish) adolescents learning English in high-school over a two-year period. Accordingly, data were collected at two testing times with an interval of two years between Time 1 (henceforth T1), when all learners were 13, and Time 2 (henceforth T2), when all learners were 15 . Until age 12, the learners in both groups receive the same amount of English as a Foreign Language (henceforth EFL) classes. At that age, one of the groups starts receiving CLIL lessons in addition to the regular EFL classes (we will refer to this group as CLIL group) while the other group simply goes on with the EFL lessons (we will refer to this group as EFL group).

In our analysis we consider the main elements that are needed to develop the morphological structure of the English sentence (the distribution of lexical and auxiliary verbs, verbal inflection and use of pronouns) and we also measured syntactic complexity (rates of coordinate and subordinate sentences). By analysing these elements we endeavour to learn more about the morphosyntactic development of English in school contexts, to explore the possible effects of increasing exposure at age 12 by means of CLIL lessons and to pin down which aspects of morphosyntax (if any) can be included in the general advantages in proficiency reported for CLIL learners, thus contributing to reconcile previous findings. As both CLIL and morphosyntactic development are widely researched topics we will also be 
able to compare our results to those of previous works and to complete and qualify some of their findings.

\subsection{Literature review}

\subsubsection{General Findings on morphosyntactic development}

From the different domains of study in the field of Second Language Acquisition (henceforth SLA), the study of the acquisition of morphosyntax has always had the lion's share. Not only is there a wealth of studies on this topic but it has also been suggested that this area of research, with the morpheme acquisition studies in the 1970s, inaugurated the establishment of SLA as an autonomous field. On the other hand, English is by far the most studied language (Larsen-Freeman, 2010). Thus, the acquisition of English morphosyntax is probably the most widely researched topic in the field. Three issues from this prolific area of research are of special interest for the present paper: (i) the common route of development; (ii) pervasive morphological inaccuracies and, (iii) different rates of acquisition.

The "common route" of development, also referred to as the "natural order" (Krashen, 1988), was probably the first and most fascinating finding in the field. The idea that all learners acquire English morphemes in virtually the same order (Corder, 1967; Dulay and Burt, 1974) and that this order shows substantial similarities with English children acquiring their L1 (Brown, 1973) triggered a barrage of studies. Gradually, researchers have found many differences among the purported similarities. These differences are attributable to a variety of factors among which the influence of the L1 has been generally considered the most important one (Goldschneider and DeKeyser, 2005). In other words, learners sharing the same L1 acquire grammatical morphemes in the same order and, when compared to the natural order, they acquire a grammatical morpheme earlier when the equivalent category is present in their native tongue (Luk and Shirai, 2009).

A second striking finding in the field has been that general proficiency surpasses morphological accuracy. Learners who achieve high levels of proficiency in the target language still show difficulties with inflection (Lardiere, 2000; Todeva, 2010). Likewise, when analysing syntax and morphology separately, it has been found that while syntax increases in complexity along with proficiency morphology lags behind (Ellis, 1984; Iwashita, 2006; Ortega, 2003). The difficulties with morphology show up in learners' performance in the form of omissions, use of erroneous morphemes, fluctuation of provision/omission of a particular morpheme in the same learner, etc. (Larsen-Freeman, 2010; Long, 2003). Developing the metaphor of the route, it could be said that the learners progress faster and more regularly on the route towards proficiency while they progress more slowly on the route towards morphological accuracy, a route in which they even seem to stop and step back at certain times. 
The third main finding is that research has found great differences in learners' rate of acquisition (speed of acquisition). These differences seem to hinge on multiple variables (learning context, age, linguistic background, mother tongues, etc.). Among these variables, the type of instruction has been widely recognized as greatly influential (Bongartz, 2003; Ellis, 1984; Norris and Ortega, 2000) and the study of how it intersects with acquisition has, in fact, been a major issue in SLA (Larsen Freeman, 2010). Besides, as schools probably have one of the largest populations of foreign language learners, at least in the initial stages, this constitutes a valuable and ecological instructional context to explore.

\subsubsection{Morphosyntactic development in school contexts}

Within school contexts, several researchers have found an advantage for older EFL learners (García Mayo and García Lecumberri, 2003; Lázaro Ibarrola, 2002; Muñoz, 2006) - an advantage already reported by Fathman (1975) and Krashen, Long and Scarcella (1979) for other settings-. This suggests that it is age, rather than amount of exposure, what leads morphological development. Muñoz (2006) compared six groups of instructed learners of English in Barcelona and found that older learners showed a faster rate of acquisition and higher accuracy in morpheme production. García Mayo and Lázaro Ibarrola (2005), García Mayo, Lázaro Ibarrola and Liceras $(2005,2006)$ and Lázaro Ibarrola (2002) in an analysis of the morphological development of Basque/Spanish bilinguals learning English at school found that students exposed to similar amounts of input but with different onsets of exposure reached significantly different stages with older learners significantly outperforming younger ones. They also claimed that their learners speeded their morphological development around the age of 12-13 and suggested that this acceleration was triggered by the acquisition of the pronominal system, which was fully achieved at around age 15. At this age, the learners held back their acceleration and only maintained their morphological achievements until the end of the school period (at age 18), which might be interpreted in line with the general finding on pervasive grammatical inaccuracies mentioned above. With a more extreme view, Rifkin (2005) in a study of instructed second language acquisition of Russian suggested that there is a ceiling effect in traditional classroom foreign language instruction, that is, learners reach a point of development and seem to stagnate and be unable to progress beyond this point.

In conclusion, three main findings could be highlighted from research in the school context: age rather than amount of exposure seems to lead morphological development with a clear advantage for older learners; morphological development speeds up around ages 12-13; and, finally, following the studies by García Mayo et al. $(2005,2006)$ and Lázaro Ibarrola (2002), learners seem to decelerate morphological development around age 15 with inaccuracy rates which are far from native or, conversely, following Rifkin's (2005) study for Russian, learners will not decelerate but fossilize. 


\subsubsection{Morphosyntactic development in CLIL contexts}

Research on the acquisition of morphosyntax in CLIL settings still remains scarce and has led to conflicting results. On the one hand, Dalton-Puffer (2008), in an attempt to identify which aspects of language competence are more developed in CLIL contexts, places morphology among the ones which are favourably affected. This author suggests that an effect of the increased amount of contact with the language can be observed on some aspects of English morphology, particularly in low-level processes like the third person $-\mathrm{s}$ or irregular past tense. Similarly, Ruiz Zarobe (2008) in a longitudinal analysis of the oral narratives of Basque/Spanish bilinguals learning English in school also finds that CLIL groups outstrip non-CLIL groups both as regards general proficiency and as regards grammatical accuracy. On the contrary, the very few studies concentrating on very specific morphological aspects have not reached the same conclusion. Bongartz (2003) in a study focusing solely on the acquisition of German noun phrases by $2^{\text {nd }}$ and $5^{\text {th }}$ graders finds that more exposure to German in an immersion context with young children does not correspond to higher accuracy rates. Likewise, García Mayo and Villarreal Olaizola (2011) in an empirical study with adolescents, also comparing CLIL vs. non-CLIL students in the Basque Country, found no significant differences when looking at affixal and suppletive forms. It seems that studies on the provision of specific morphemes pose a serious challenge to the general claims about morphological advantages in CLIL groups.

\section{METHOD}

\subsection{Participants and Procedure}

The present study analyses data from 26 Basque-Spanish bilinguals learning English in highschool. They are divided in two groups: (i) A CLIL group of 15 students who receive EFL and CLIL instruction. (ii) An EFL group of 11 students who only receive EFL instruction. Each participant narrated the story "Frog, where are you?" (Mayer, 1969) at two testing times with a two-year interval between $\mathrm{T} 1$ and $\mathrm{T} 2$. The oral production was recorded and codified in CHILDES (MacWhinney, 1991) format.

When data were collected for the first time, that is, at T1, they were all 13 years old, they were enrolled in the second of 4 years of Compulsory Secondary Education and they had been learning EFL for 8 school years, having three lessons per week. In addition to these three hours of EFL, the CLIL group had received CLIL instruction for one year, having 4 hours of CLIL instruction per week.

Two years later, at T2, all students were 15 years old and they were in the $4^{\text {th }}$ year of Compulsory Secondary Education. By then, they had all received regular English classes for 10 years. In addition, the CLIL group had also received CLIL instruction for 3 school years. 
Thus, we have two groups of students of the same age who share a similar amount of exposure to English in school until they are 12. At this age the learners in the CLIL group increase the amount of exposure to English in the form of CLIL lessons while the learners in the EFL group do not.

As for data analysis, the following elements were coded: (i) Sentences with auxiliary and independent lexical verbs; (ii) verbal inflection in obligatory contexts; (iii) correction and variety in the use of the pronominal system; (iv) coordinate and subordinate clauses (syntactic complexity). Quantitative analyses were combined with closer examinations of the data when necessary to interpret our results. As regards statistical analysis, one-sample and two sample binomial tests were used and all tests were carried out at the 5\% significance level. All examples in this article come from data collected from the current study. The participants' names are not mentioned and they are identified with the name of the group (CLIL/EFL), the testing time (T1/T2) and a number. For example (CLIL, T1, P6) means the example comes from participant number 6 , at time 1 , in the CLIL group.

\subsection{Research questions}

With the present study we are analysing data from a CLIL and an EFL group of students of similar age at two testing times with an interval of two years between T1 and T2. We are looking at the development of the morphological structure of sentences and at syntax complexity. Therefore, our research questions are the following:

(i) Will the learners in both groups reach similar stages of morphosyntactic development regarding the aspects under observation at $\mathrm{T} 1$ and at $\mathrm{T} 2$ ?

(ii) Will the learners in both groups show the same rate of progress regarding the aspects under observation between testing times?

Based on the theoretical background presented above, (i) we expect CLIL learners to be faster (Dalton-Puffer, 2008; Ruiz Zarobe, 2008), but perhaps not in all aspects (Bongartz, 2003; García Mayo and Villarreal Olaizola, 2011), and (ii) we expect that both groups will progress between testing times, will show difficulties with morphology (Lardiere, 2000; Todeva, 2010) and will also show signs of deceleration or fossilization (García Mayo et al., 2005, 2006; Rifkin, 2005).

\section{RESULTS}

This section features the analysis of the results regarding the four aspects mentioned above. Before presenting them, it is interesting to point out that the overall production of the CLIL group was slightly higher than that of the EFL group (CLIL group T1: 3646 words, T2: 3719; 
EFL group T1 31230, T2: 3167). This could be taken as the first sign of superiority in the CLIL group.

\subsection{Sentences with independent lexical verbs}

From the total number of sentences in the learners' performance we analysed the percentage of sentences with copula be, as in (1), with auxiliary be, as in (2) and with independent lexical verbs, as in (3). Table 2 presents the results.

(1) The frog is not on the cup (CLIL, T2, P13).

(2) He's looking for the frog (CLIL, T1, P6).

(3) The frog lives in a pot (EFL, T2, P1).

\begin{tabular}{|c|c|c|c|c|}
\hline \multirow{2}{*}{ Sentence Types } & \multicolumn{2}{|c|}{ T1 } & \multicolumn{2}{|c|}{ T2 } \\
\cline { 2 - 5 } & CLIL & EFL & CLIL & EFL \\
\hline Copula be & $19.69 \%$ & $14.33 \%$ & $18.96 \%$ & $21.12 \%$ \\
& $(90 / 457)$ & $(42 / 293)$ & $(84 / 443)$ & $(68 / 322)$ \\
\hline Auxiliary be & $5.25 \%$ & $5.80 \%$ & $4.74 \%$ & $6.21 \%$ \\
& $(24 / 457)$ & $(17 / 293)$ & $(21 / 443)$ & $(20 / 322)$ \\
\hline Lexical verbs & $75.05 \%$ & $79.86 \%$ & $76.29 \%$ & $72.67 \%$ \\
& $(343 / 457)$ & $(234 / 293)$ & $(338 / 443)$ & $(234 / 322)$ \\
\hline
\end{tabular}

Table 1: Sentence types.

As Table 1 shows, the highest rate corresponds to sentences with independent lexical verbs and there are no relevant differences between groups or testing times. This distribution has been long acknowledged in previous SLA works with L2 and L1 students (Dulay and Burt, 1974; Lakshmanan, 1994; Lázaro Ibarrola, 2002). These studies have shown that increase in proficiency corresponds to an increase in the ability to produce sentences with independent lexical verbs. On the contrary, at earlier stages of acquisition learners constantly use be forms (mainly is) to produce a sentence. In the present study, it seems that the students in both groups have a sufficient command of English to produce sentences with independent lexical verbs at both testing times. In other words, in the route of acquisition these students have already gone past the stage where learners need the verb be to project sentences (García Mayo et al., 2005).

However, in stark contrast to this, 13 instances of placeholder "is" were found in the EFL group (7 at T1 and 6 at T2). Placeholder "is" is a structure typically found in the initial stages of the acquisition of English. As can be seen in example (4), it consists of the insertion of the form "is" before the main verb.

(4) The boy is look (EFL, T1, P8). 
This structure has been found in children learning English as a second or foreign language (Eubank, 1993, 1994; García Mayo et al. 2005; Ionin and Wexler, 2002; Lakshmanan, 1994; Lázaro Ibarrola, 2002) and also in native children (Radford, 1997; Roeper, 1992) but always in initial stages of acquisition. García Mayo et al. (2005) argue that the youngest learners use placeholder "is" to hold inflection. Later, participants progress to another stage in which they use independent lexical verbs without placeholder "is" and inflection increases (García Mayo et al., 2006). Thus, it seems that the students in the two groups of the present work are already at the stage when learners are able to produce sentences with independent lexical verbs but 13 instances of a structure typical of earlier stages still remains in the EFL group. This gives the impression that this group has not entirely left the nest of the previous stage and can thus be taken as the second sign of an advantage for CLIL students. The first was larger production.

\subsection{Verbal inflection}

Table 2 presents the results regarding the rates of inflected verbs in obligatory contexts ${ }^{1}$. Within inflected verbs we have included the three possible types of inflection: third person singular, as in (5), regular past, as in (6) and irregular past, as in (7).

(5) The frog lives in a pot (EFL, T2, P1).

(6) And at night the frog disappeared (CLIL, T2, P9).

(7) And took one of the child and went to the home (EFL, T1, P11).

\begin{tabular}{|c|c|c|c|c|}
\hline \multirow{4}{*}{ Inflected lexical verbs } & \multicolumn{2}{|c|}{ T1 } & \multicolumn{2}{|c|}{ T2 } \\
\cline { 2 - 5 } & CLIL & EFL & CLIL & EFL \\
\cline { 2 - 5 } & $51.20 \%$ & $42.16 \%$ & $68.44 \%$ & $37.06 \%$ \\
& $(107 / 209)$ & $(86 / 204)$ & $(193 / 282)$ & $(73 / 197)$ \\
\hline
\end{tabular}

Table 2: Rates of inflection in obligatory contexts.

As Table 2 shows the provision of inflection is higher in the CLIL group at both testing times. This difference is slightly significant at $\mathrm{T} 1 \quad(\mathrm{p}$-value: $<0.007)$ and clearly more significant at T2 (p-value: $<0.001$ ). This means that the CLIL group overtakes the EFL group at $\mathrm{T} 1$ and increases the distance during the two-year interval (after age 13).

Regarding the progression of each of the groups over the two-year period, in the EFL group the number of inflected verbs remains stable, that is, inflection does not progress between testing times, although the percentage slightly drops at T2 (T1: 42.16\%; T2:37.06\%) a statistical analysis shows that this drop is non-significant (p-value: < 0.93 ). On the contrary, the provision of inflection significantly increases in the CLIL group (T1: $51.20 \%$; T2: $68.44 \%)(\mathrm{p}<0.00001)$, however, this progression can be qualified by a closer analysis of the data, i.e. by looking at the distribution of affixal inflection and irregular past separately. 
As morpheme order studies have shown, English irregular past forms are acquired before affixal morphemes both by L1 learners (Brown, 1973) and by EFL learners (Krashen, 1978; Lázaro Ibarrola, 2002). This seems to be the case because they correspond to different types of processing: learning lexical items vs. being able to regularly provide an affix in a particular context (Zobl, 1998). Table 3 displays the distribution of affixal and irregular inflection.

\begin{tabular}{|c|c|c|c|c|}
\hline \multirow{2}{*}{ Distribution of inflection } & \multicolumn{2}{|c|}{ T1 } & \multicolumn{2}{c|}{ T2 } \\
\cline { 2 - 5 } & CLIL & EFL & CLIL & EFL \\
\hline \multirow{2}{*}{ Affixal (-s; -ed) } & $33.01 \%$ & $27.45 \%$ & $34.04 \%$ & $23.35 \%$ \\
& $(69 / 209)$ & $(56 / 204)$ & $(96 / 282)$ & $(46 / 197)$ \\
\hline \multirow{2}{*}{ Irregular Past } & $18.18 \%$ & $11.27 \%$ & $34.39 \%$ & $14.72 \%$ \\
& $(38 / 209)$ & $(23 / 204)$ & $(97 / 282)$ & $(29 / 197)$ \\
\hline
\end{tabular}

Table 3: Distribution of affixal and irregular inflection in obligatory contexts.

As can be observed in Table 3, the most striking finding is that, while the CLIL group produces a similar percentage of affixal morphemes at both testing times (T1: 33,01\%; T2: $34,04 \%$ ), the percentage of irregular past forms in this group grows very importantly at T2 (T1: 18,18\%; T2: 34,39\%). This means that the higher number of inflected forms in the CLIL group at T2 is mainly due to a higher provision of irregular forms while affixal inflection remains stable. This result would go in line with García Mayo and Villarreal (2011) who found no differences as regards affixal inflection when comparing CLIL and EFL students.

On the contrary, the EFL group produces similar percentages of affixal and irregular past forms at both testing times. Thus, there are no signs of evolution over the two year period in this group: There is no change in production rates (Table 2), and no change in the distribution of affixal and irregular past forms (Table 3).

In conclusion, the CLIL group seems to be one step ahead as regards overall provision of inflection and this is mainly due to higher provision rates of irregular past forms. Again, we are before an indicator of superiority in the CLIL group, as was the case with the larger production and the fact that CLIL learners have not used placeholder "is".

\subsection{Pronominal system}

The findings regarding the use of pronouns will be considered from two perspectives: correction and variety. Table 4 presents correction rates: 


\begin{tabular}{|c|c|c|c|c|}
\hline \multirow{4}{*}{$\begin{array}{c}\text { Correct pronominal use } \\
\text { over total number of pronouns }\end{array}$} & \multicolumn{2}{|c|}{ T1 } & \multicolumn{2}{c|}{ T2 } \\
\cline { 2 - 5 } & CLIL & EFL & CLIL & EFL \\
\cline { 2 - 5 } & $87.55 \%$ & $66.10 \%$ & $90.71 \%$ & $84.17 \%$ \\
& $(239 / 273)$ & $(78 / 118)$ & $(293 / 323)$ & $(117 / 139)$ \\
\hline
\end{tabular}

Table 4: Correction rates in the use of pronouns.

The first observation to be made is the fact that the CLIL group has an overall higher number of pronouns at both testing times (CLIL, T1: 273; T2: 323 vs. EFL, T1: 118; T2: 139). This partly correlates with the higher number of words in this group but the number of pronouns is over twice as much as the number in the EFL group, which suggests that this group prefers to use subject pronouns rather than noun phrases and, in turn, this suggests that the acquisition of the pronominal system is more advanced than in the EFL group.

In line with this, Table 4 shows that the correction rate is higher in the CLIL group at both testing times. As for progression over the two years, the correction rate grows very significantly in the EFL group (p-value: $<0.0001$ ) and, as a result, at T2 this group reaches a very similar rate to that of the CLIL group at T1 (CLIL, T1: 87.55\%; EFL, T2: 84.17\%). In fact, the difference between groups is clearly significant at T1 (T1: p-value: $<0.0001)$ but only slightly significant at T2 (T2: p-value: <0.04). It would seem that the EFL group is following the CLIL one two years later. On the other hand, the CLIL group also presents signs of progression between testing times, although more moderately ( $p$-value: <0.00001).

Finally, it is also noteworthy to say that 7 instances of placeholder "he" have been found in the EFL group at T1. This structure consists of the insertion of a pronoun, usually "he", before the main verb and with a noun phrase functioning as subject. We illustrate this with one example in (8).

(8) And the boy he rescue (EFL, T1, P2).

Previous studies have also found this structure in English L2 (García Mayo et al., 2005; Fuller and Gundel, 1987; Lázaro Ibarrola, 2002). Lázaro Ibarrola (2002) and García Mayo et al. (2005) propose that this structure corresponds to the initial stages of acquisition of the pronominal system and it gradually disappears as the full pronominal system is acquired. As in the case of placeholder "is", this structure has been said to function as a replacement of verbal morphemes (or lack of them) that have not been acquired yet. Although the number is very small (7 instances) again the EFL group seems to retain several instances of a structure that belongs to earlier stages of acquisition.

As for pronoun variety, Table 5 features data illustrating that characteristic of the learners' production by concentrating on the distribution of pronoun "he". 


\begin{tabular}{|c|c|c|c|c|}
\hline \multirow{2}{*}{ Pronouns } & \multicolumn{2}{|c|}{ T1 } & \multicolumn{2}{c|}{ T2 } \\
\cline { 2 - 5 } & CLIL & EFL & CLIL & EFL \\
\hline \multirow{2}{*}{$\mathrm{He}$} & $47.99 \%$ & $55.93 \%$ & $29.72 \%$ & $53.24 \%$ \\
& $(131 / 273)$ & $(66 / 118)$ & $(96 / 323)$ & $(74 / 139)$ \\
\hline \multirow{2}{*}{ Other Pronouns } & $52.01 \%$ & $44.06 \%$ & $70.27 \%$ & $46.76 \%$ \\
& $(142 / 273)$ & $(52 / 118)$ & $(227 / 323)$ & $(65 / 13)$ \\
\hline
\end{tabular}

Table 5: Use of pronoun "he" vs. other pronouns.

As Table 5 shows, in both groups "he" is the most common pronoun. First of all, this is the case because of the nature of the story in which a boy is the main character. However, most of the cases of incorrect use of pronouns correspond to the use of "he" as a default pronoun, as in (9).

(9) Then he eh the boy and the dog went to the forest eh to look for it. (CLIL, T2, P1).

As was the case for the placeholder "he" found in the EFL group, the use of "he" as a default pronoun is a typical feature at the onset of the acquisition of the pronominal system (Lázaro Ibarrola, 2002; Muñoz, 1994; Selinker, 1972). Accordingly, the evolution of pronoun variety between testing times can be traced by looking at the rates of use of pronoun "he": If this pronoun drops this can be taken as a sign of increasing use of other pronouns and, in turn, increase in variety.

As can be seen in Table 5, in the EFL group, the pronoun "he" remains at a similar rate (over 50\% percent) at both testing times (T1: 55,93\%; T2: 53,24\%) and this difference is statistically non-significant (test statistic: 0,59; p-value: <0,28). On the contrary, if we look at the CLIL group, the rate of production of this pronoun is lower than it is in the EFL group and drops very significantly at T2 (from $47,99 \%$ to $29,72 \%$; Test statistic: 6.6 p-value $<0.001$ ). This drop means that other pronouns are being used more frequently. In conclusion, pronoun variety is larger in the CLIL group and this variety grows very importantly between both testing times. By contrast, there is no increase in variety in the EFL group.

The results about correction presented in Table 4 can be now completed. The CLIL group does not only moderately increase correction rates over the two year period but there is also a very important growth in variety. On the other hand, the EFL group increases correction rates (reaching at $\mathrm{T} 2$ those of CLIL learners at T1) but does not display a greater variety of pronouns. Once again, both groups seem to be at different points in the route and the EFL group seems to be following one step behind.

To sum up, the CLIL group outperforms the EFL group regarding quantity of production, absence of placeholders, verbal inflection and, as shown in this section, correction and variety in their use of pronouns. 


\subsection{Subordinate Sentences}

A final aspect we have considered is syntax complexity by analysing the distribution of coordinate and subordinate clauses. Table 6 presents this information.

\begin{tabular}{|c|c|c|c|c|}
\hline \multirow{2}{*}{$\begin{array}{c}\text { Types of } \\
\text { Complex Sentences }\end{array}$} & \multicolumn{2}{|c|}{ T1 } & \multicolumn{2}{|c|}{ T2 } \\
\cline { 2 - 5 } & CLIL & EFL & CLIL & EFL \\
\hline \multirow{2}{*}{ Subordinate Sentences } & $14.08 \%$ & $4.76 \%$ & $37.23 \%$ & $19.92 \%$ \\
& $(39 / 277)$ & $(11 / 231)$ & $(86 / 231)$ & $(52 / 261)$ \\
\hline \multirow{2}{*}{ Coordinate Sentences } & $85.92 \%$ & $95.23 \%$ & $62.77 \%$ & $80.07 \%$ \\
& $(238 / 277)$ & $(220 / 231)$ & $(145 / 231)$ & $(209 / 261)$ \\
\hline
\end{tabular}

Table 6: Coordinate and Subordinate Sentences.

As can be seen in Table 6, the CLIL group produces a significantly higher number of subordinate sentences at both testing times (T1: p-value: < 0. 0001; T2: p-value: < 0.001). Besides, the EFL group has an extremely low number of subordinate sentences at T1 $(11 / 231=4.76 \%)$. This can be taken as a sign of a lower level of proficiency (Serra, 2007). However, at T2, the number of subordinate sentences grows very significantly in both groups (CLIL: $\mathrm{p}<0.00001$; EFL: $\mathrm{p}<0.0001$ ) and, as was the case with pronoun correction, the EFL group seems to reach at T2 the percentage of the CLIL group at T1. Again, the CLIL group seems to be more advanced in the route of acquisition but the EFL group seems to be following the same path two years later.

Greater syntactic complexity is the last indicator that the CLIL group has run faster and further in the route of English morphosyntax.

\subsection{Overall comparison of CLIL vs. EFL}

To finish this section, we proceed to summarize the results. The greater number of sentences with independent lexical verbs has been the only aspect showing similarities in both groups (although 14 instances of placeholder is were found in the EFL group). This indicates that the learners have a sufficient command of English to produce sentences with independent lexical verbs, a finding in line with previous studies, as the dependence on auxiliary verbs to project sentences has only been reported at very initial stages of acquisition and with younger children. Apart form this, in all other aspects, both groups have behaved quite differently.

On the one hand, CLIL students have displayed higher rates of inflected verbs and a significant increase in the provision of inflection mainly located in the provision of irregular past forms. This group also has higher correction rates in the use of pronouns and these rates grow moderately yet significantly and along with a very significant increase in variety, which suggests that the pronominal system is entering in advanced stages of acquisition. It is also noteworthy that the total number of pronouns is higher in this group and that no instances of 
placeholder "he" were found. As for syntactic complexity, CLIL students are able to produce an important number of subordinate sentences already at $\mathrm{T} 1$ and these sentences significantly increase at $\mathrm{T} 2$, which can be taken as a sign of increasing syntactic complexity and increasing proficiency.

On the other hand, EFL students display lower inflection rates and no sign of growth or evolution of this aspect between testing times. On the contrary, this group significantly develops in all other aspects observed. Regarding pronouns, the correction rates are lower in this group but there is a very significant growth at T2 almost reaching the percentages that the CLIL group had reached at T1. However, there is no increase in variety. In addition, some instances of placeholder "he" were found suggesting that, especially at $\mathrm{T} 1$, these learners are still at the initial stages in the acquisition of the pronominal system. Finally, these students are barely able to produce subordinate sentences at $\mathrm{T} 1$ which can be taken as an indicator of lower proficiency levels. Despite this finding, the growth at T2 is very significant and, again, it reaches a percentage which is similar to that of the CLIL group at T1. In conclusion, the students in the EFL group are moving on in the acquisition of morphosyntax and the provision of inflection seems to be the only aspect which shows no signs of development.

\section{DISCUSSION}

In this section we will concentrate on the implications that the results reported on above might have in connection to the literature review offered at the beginning of this paper. In order to do so, we would like to summarize our results by placing CLIL and EFL students in the route of acquisition. Figure 1 depicts this route by placing EFL students first (on the left) and CLIL students after them (on the right) as if we were before the evolution of a single group.
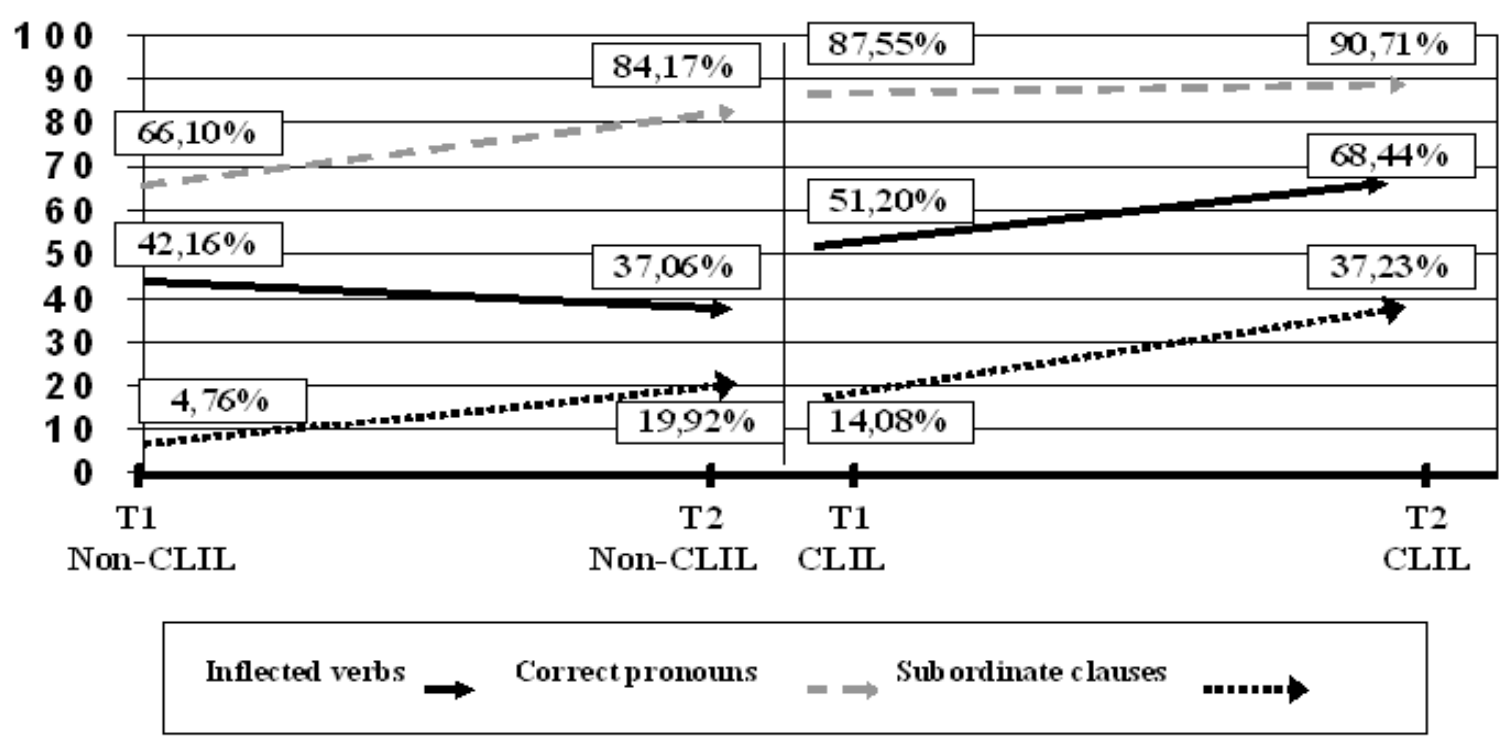

Figure 1. Non-CLIL and CLIL results. 
As Figure 1 shows, it seems that the CLIL students are one step ahead while EFL students are following in their footsteps two years later. In other words, EFL students at age 15 reach the performance that CLIL students already had when they were two years younger, that is, at $\mathrm{T} 1$ when they were 13.

Thus, the learners in the present study clearly follow the same route of acquisition (Krashen, 1988) and differ in their learning rate. This reinforces the idea that the L1 guides the order of acquisition (Luk and Shirai, 2009) and that instruction does make a difference in terms of rate (Bongartz, 2003; Ellis, 1984; Norris and Ortega, 2000), in this case, with a clear advantage for learners receiving CLIL instruction. In turn, these results can also help to reconcile previous findings about the acquisition of morphosyntax in CLIL vs. non-CLIL contexts. In line with Ruiz Zarobe (2008), we have also found that CLIL learners clearly outstrip EFL learners but a qualitative analysis of inflection has shown that, in line with García Mayo and Villarreal Olaizola (2011), while this advantage is clearly found in the provision of irregular forms it is very limited when analysing the provision of affixal morphemes.

On the other hand, we have also found pervasive inaccuracies (Lardiere, 2000; Todeva, 2010) in the provision of inflection in both groups. Correct inflection rates (T2- CLIL: 68.44\% and EFL: $37.06 \%$ ) are very far from native and very far from the correct provision of pronouns in both groups (T2- CLIL: 90.71\%; EFL: $84.17 \%)^{2}$. Also, the progression of inflection is not comparable to the progression of syntax, in line with those studies claiming that while syntax seems to grow along with proficiency morphology lags behind (Ellis, 1984; Iwashita, 2006; Ortega, 2003).

In fact, in the EFL group inflection does not grow at all, which might give the impression that these learners may have reached a ceiling (Rifkin, 2005) as regards this particular aspect. However, as learners in the EFL group improve all other aspects and, as this group seems to be clearly following the same progression of the CLIL group two years later, the expectation would be that in two years in the EFL group, inflection will increase together with pronoun correction and variety (as has been the case in the CLIL group). This would, in turn, discard the possibility of fossilization. In our view, EFL students are, in fact, holding up the provision of inflection until another aspect is developed: the pronominal system. This explanation would go in line with Lázaro Ibarrola (2002) and García Mayo et al. (2005, 2006) who also found that when learners fully acquire the pronominal system, inflection started to grow. The explanation was that Basque-Spanish learners of English initially transfer the structure from their L1s and analyse the pronominal system of English as a placeholder for inflection, thus, only when pronouns are reanalysed inflection can be fully acquired. We suggest that the pronominal system be included in the morpheme order acquisition studies, as they seem to be a key driver of the acquisition of English morphology and can, in fact, be analysed as morphemes ${ }^{3}$ (García Mayo et al., 2005; Lázaro Ibarrola, 2002). In short, in our 
view, pronouns are the missing link in the morpheme order studies. Future research could consider the in-depth investigation of their place and role on the route of acquisition.

The present study also has important implications for previous works focusing on the influence of age and amount of exposure in school contexts. Most research in EFL school contexts has shown that older is better and that age seems to be stronger than amount of exposure (García Mayo \& García Lecumberri, 2003; Lázaro Ibarrola, 2002; Muñoz, 2006). This means that, under similar hours of exposure to the foreign language in classroom settings, older children fare better. While previous studies have compared different age groups (see the oft-cited revision of studies on age in Singleton and Ryan, 2004), the data presented here compares two groups of similar age. Both groups receive a similar amount of exposure to English until age 12-13 but one group increases exposure after that age. This increase happens in the form of CLIL lessons. Consequently, the present study can complete and qualify previous findings. Our results have indicated that learners with larger amount of exposure (CLIL group) have reached significantly further stages of development (as regards inflection, use of pronouns and of subordinate clauses) than learners of the same age with smaller amounts of exposure (EFL group). In other words, increased exposure in the form of CLIL lessons starting at age 12 has meant a faster rate of acquisition. Thus, amount of exposure seems to have been more relevant than age.

In our view, these results also enhance the importance of the age at which different amounts of exposure are provided. In the present study the different amounts of exposure have started at age 12 (when one of the groups started with CLIL lessons). At this age, cognitive development is mature enough to translate larger amounts of exposure into a faster learning rate. Lázaro Ibarrola (2002) also pointed at age 12-13 as the age at which morphosyntactic acquisition speeds up $^{4}$. We suggest that larger amounts of exposure to English in a school context could make a (greater) difference after a certain stage of cognitive development but not (or not so clearly) before that stage. In fact, lack of success of larger amounts of exposure at earlier stages has already been reported (Bongartz, 2003; Lázaro Ibarrola, 2002; Muñoz, 2006). Further exploring this possibility could be of great interest for researchers and also for practitioners. All in all, if increasing amounts of exposure only lead to faster morphosyntactic development after age 12 doing so before that age might be a futile attempt ${ }^{5}$ In short, the superiority of older learners is an important finding and now we add the possibility that this superiority enables them to translate larger amounts of exposure into a faster learning rate. In layman's terms: the findings in the present study seem to point to the idea that in school contexts only children who are 12 and up will learn more English grammar if they have more English lessons. 


\section{CONCLUSIONS}

This study has reported on the oral production of two groups of English learners, a CLIL and an EFL group, at two testing times over a two-year period, between ages 13 and 15 . Regarding progression between testing times, despite inaccuracies in inflection and based on the interpretation of pronouns as placeholders for inflection and as key drivers in the acquisition of morphosyntax, we have found no signs of fossilization, thus challenging previous claims in school contexts. On the other hand, when comparing both groups, we have found a clear advantage for CLIL learners in all the aspects under observation, thus enhancing the value of increased exposure in the form of CLIL lessons at the age of 12. Thus, in future work, the combination of older age and increase in exposure as well as the inclusion of the pronominal system when analysing morphosyntactic development would be some of the crucial lines for future research.

To conclude, it is our belief that the positive results of the CLIL group lend further support for CLIL methodologies, as they can provide more exposure to foreign languages at school in order to promote successful language learning without sacrificing time from other areas of the school curriculum.

\section{ACKNOWLEDGEMENTS}

This study was supported by grants IT311-10 (Basque Government) and CSC2007-00012, HUM200609775-C02-01/FILO (Spanish Ministry of Education), which are hereby gratefully acknowledged.

Thanks also go to Prof. Vicente Núñez Antón (Department of Econometrics and Statistics - University of the Basque Country) for his assistance with the statistical analysis of the data.

\section{NOTES}

1. While we are able to establish third person singular as an obligatory context for inflection, due to the nature of our oral narratives we cannot establish if the context requires present or past forms. The learners could choose to narrate in either tense and in their performance they often shift form one tense to the other in the same excerpt.

2. Following Brown (1973) the cut-off point to say that a morpheme has been acquired would be $90 \%$.

3. In our view, pronouns are, in fact, far more crucial to sentence structure in English than the article, which has typically been included in the morpheme order studies.

4. This age (12) also corresponds to the age at which studies from the field of cognitive development locate the formal operational stage (Piaget, 1964). This is the final stage and it entails abstract thinking, logical reasoning, ability to hypothesize and draw conclusions from the available input, etc. All of which probably favour the acquisition of morphosyntax.

5. Obviously, in the present work we are concentrating solely on the acquisition of morphosyntax and not on the possible effects of larger exposure at early ages on other aspects. However, previous works have highlighted the advantage of older learners in virtually all areas: morphology, syntax, semantics and sometimes phonology (Muñoz, 2006) 


\section{REFERENCES}

Berman, R. \& Dan, S. (1994). Relating events in narrative: A crosslinguistic developmental study. Hillsdale, NJ: Lawrence Erlbaum.

Bongartz, C. (2003). Grammar growth and L1 transfer: On accuracy development in immersion programs. In J. Rymarczyk \& H. Haudeck (Eds.), In search of the active learner (pp. 99-115). Frankfurt a. M.: Peter Lang.

Brown, R. (1973). A First Language: The Early Stages. London: George Allen \& Unwin Ltd.

Corder, P. (1967). The significance of learner errors. International Review of Applied Linguistics, 5, 161-170.

Coyle, D. (2007). Content and language integrated learning: Toward a connected research agenda for CLIL pedagogies. The International Journal of Bilingual Education and Bilingualism, 10, 543562

Dalton-Puffer, C. (2008). Outcomes and processes in content and language integrated learning (CLIL): current research from Europe. To appear in W. Delanoy \& L. Volkmann (Eds.), Future perspectives for English language teaching (pp.139-157). Heidelberg: Carl Winter.

Dalton-Puffer, C., Nikula, T. \& Smit, U. (Eds.). (2010). Language Use and Language Learning in CLIL Classrooms. Netherlands: John Benjamins.

Dulay, H. \& Burt, M. (1974). Natural sequences in child second language acquisition. Language Learning, 24, 37-53.

Ellis, R. (1984). Can syntax be taught? A study of the effects of formal instruction on the acquisition of WH questions by children. Applied Linguistics, 3(3), 138-155.

Eubank, L. (1993). On the transfer of parametric values in L2 development. Language Acquisition, 3, 183-208.

Eubank, L. (1994). Towards an explanation for the late acquisition of agreement in L2 English. Second Language Research, 10, 84-93.

Fathman, A. (1975). The Relationship between Age and Second Language Productive Ability. Language Learning, 21, 245-253.

Fuller, J. \& Gundel, J. (1987). Topic prominence in interlanguage. Language Learning, 37, 1-18.

García Mayo, M. P. \& Garcia Lecumberri, M. L. (2003). Age and the Acquisition of English as a Foreign Language. Clevedon: Multilingual Matters.

García Mayo, M. P. \& Lázaro Ibarrola, A. (2005). Pronouns revisited: Evidence from the morphosyntactic development of English as an L3. In F. Garrudo Carabias \& J. Comesaña Rincón (Eds.), Estudios de Filología Inglesa en honor de Antonio Garnica (Serie: Lingüística. N. 25) (pp. 217-228). Sevilla: Universidad de Sevilla.

García Mayo, M. P. \& Villarreal Olaizola, I. (2011). The development of suppletive and affixal tense and agreement morphemes in the L3 English of Basque-Spanish bilinguals. Second Language Research, 27(1), 129-149.

García Mayo, M. P., Lázaro Ibarrola, A. \& Liceras, J. (2005). Placeholders in the English interlanguage of bilingual (Basque/Spanish) children. Language Learning, 55(3), 445-489.

García Mayo, M. P., Lázaro Ibarrola, A. \& Liceras, J. (2006). Agreement in the interlanguage of Basque/Spanish bilingual children: A minimalist farewell to pro. International Journal of Applied Linguistics, 151, 83-98.

Goldshneider, J. \& DeKeyser, R. (2005). Explaining the 'natural order of L2 morpheme acquisition' in English: A meta-analysis of multiple determinants. Language Learning, 55(Supplement 1), 2677.

Ionin, T. \& Wexler, K. (2002). Why is 'is' easier than '-s'?: acquisition of tense/agreement morphology by child second language learners of English. Second Language Research, 18, 95136.

Iwashita, N. (2006). Syntactic Complexity Measures and Their Relation to Oral Proficiency in Japanese as a Foreign Language. Language Assessment Quarterly, 2, 151-170.

Krashen, S. (1978). Is the natural order an artefact of the bilingual syntax measure? Language Learning, 28, 187-191.

Krashen, S. (1988). Second Language Acquisition and Second Language Learning. New York: Prentice Hall. 
Krashen, S., Long, M., \& Scarcella, R. (1979). Age, Rate and Eventual Attainment in Second Language Acquisition. TESOL Quarterly, 13, 573-582.

Lakshmanan, U. (1994). The boy for the cookie: Some evidence for the non-violation of the case filter in child second language acquisition. Language Acquisition, 3, 51-97.

Lardiere, D. (2000). Mapping features to forms in second language acquisition. In J. Archibald (Ed.), Second language acquisition and linguistic theory (pp. 102-129). Cambridge, MA: Blackwell.

Larsen-Freeman, D. (2002). The grammar of choice. In E. Hinkel \& S. Fotos (Eds.), New perspectives on grammar teaching (pp. 103-118). Mahwah, NJ: Erlbaum.

Larsen-Freeman, D. (2010). Not so Fast: A Discussion of L2 Morpheme Processing and Acquisition. Language Learning, 60, 221-230.

Lázaro Ibarrola, A. (2002). La adquisición de la morfosintaxis del inglés por niños bilingües (euskera/castellano): Una perspectiva minimalista. Unpublished Doctoral Dissertation, University of the Basque Country, Spain.

Long, M. (2003). Stabilization and fossilization in interlanguage development. In C. Doughty \& M. Long (Eds.), Handbook of second language acquisition (pp. 487-535). Malden, MA: Blackwell.

Luk, Z. P. \& Yasuhiro, S. (2009). Is the acquisition Order of Grammatical Morphemes Impervious to L1 Knowledge? Evidence From the Acquisition of Plural -s, Articles, and Possessive's. Language Learning, 59(4), 721-754.

MacWhinney, B. (1991). The CHILDES project: Tools for analyzing talk. Hillsdale, New Jersey: Erlbaum.

Mayer, M. (1969). Frog, Where are you? New York: Dial Books for Young Readers.

Muñoz, C. (2006). Accuracy orders, rate of learning and age in morphological acquisition. In C. Muñoz (Ed.), Age and the rate of foreign language learning (pp. 107-125). Clevendon: Multilingual Matters.

Norris, J. M. \& Ortega, L. (2000). Effectiveness of L2 instruction: A research synthesis and quantitative meta-analysis. Language Learning, 50, 417-528.

Ortega, L. (2003). Syntactic complexity measures and their relationship to L2 proficiency: A research synthesis of college-level L2 writing. Applied Linguistics, 24, 492-518.

Piaget, J. (1964). Six Psychological Studies. New York: Vintage.

Radford, A. (1997). Syntactic Theory and the Structure of English. A Minimalist Approach. Cambridge: Cambridge University Press.

Roeper, T. (1992). From the initial state to V2 acquisition principles in action. In J. M. Meisel (Ed.), The Acquisition of Verb Placement (pp. 333-370). Dordrecht: Kluwer Academic Publishers.

Rifkin, B. A. (2005). A ceiling effect in traditional classroom foreign language instruction: Data from Russian. The Modern Language Journal, 89, 3-18.

Ruiz Zarobe, Y. (2008). CLIL and Foreign language learning: A longitudinal study in the Basque Country. International CLIL Research Journal, 1(1), 60-73.

Selinker, L. (1972). Interlanguage. International Review of Applied Linguistics, 10, 209-231.

Serra, C. (2007). Assessing CLIL at primary school: A longitudinal study. The International Journal of Bilingual Education and bilingualism, 10(5), 582-602.

Singleton, D. \& Ryan, L. (2004). Language Acquisition: The Age Factor. Clevedon: Multilingual Matters.

Todeva, E. (2010). Multilingualism as a kaleidoscopic experience: The mini universes within. In E. Todeva \& J. Cenoz (Eds.), The multiple realities of multilingualism (pp. 53-74). Berlin: Mouton de Gruyter.

Van de Craen, P., Mondt, K., Allain, L. \& Gao, Y. (2007). Why and how CLIL works. An outline for CLIL theory. Vienna English Working Papers, 16, 70-78.

Zobl, H. (1998). Representational changes: From listed representations to independent representations of verbal affixes. In M. L. Beck (Ed.), Morphology and its interfaces in Second Language Knowledge (pp. 339-371). Amsterdam: John Benjamins. 